divided, they will still act in keeping the edges of the wound together, and their division relieves tension and prevents ulceration. The horsehair stitche's may be retained for the full eight days.

When the stitches have all been removed, one or more strips of plaster should be applied across the lip and cheek, so as to keep the edges of the wound from separating, and also to prevent the cicatrix stretching. 'This plaster should be retained for three weeks or a month, as undue stretching of the cicatrix usually leaves a wider and more perceptible mark.

One more Hint.-When there is considerable tension after an operation for hare-lip, owing to the wideness of the cleft or deficiencies of lip tissue, the nostrils may be obstructed, and the lower lip being sucked into the mouth like a valve during respiration, the breathing may be seriously interfered with, and, therefore, such cases must be carefully watched for the first twenty-four hours after the operation, and the lower lip kept from being thus drawn in.

\section{Clefr Palate.}

True cleft palate is a congenital deformity, which may or not be associated with some form of hare-lip. Degrees as to the extent and width of the fissure are met with, and it may involve a portion only or the whole of the soft palate, or the whole soft palate with -a portion or the whole of the hard palate. In many cases the hard palate is more or less highly arched.

Treatment.-Congenital fissures of both soft and hard palates may be treated by the application of plates or artificial soft palates, but the closing of them by operation is more satisfactory, provided the patient's condition admits of the operation.

Age for Operation.-If the fissure is confined to the soft palate the operation may be performed at the age of 2 years or even earlier-I prefer the child to be at least 2 years; but when the hard palate is involved I am of opinion that the operation should be delayed until the patient is 5 years or older.

Principles of (

A. Pare the Edges of the Whole Fissure Freely.-In the soft palate this paring can readily be done, but in operating upon the hard palate it may happen that the edges of the flaps of soft texture may after their separation from the bone not be thoroughly rawed, and may therefore require a further paring.

B. Loosen Surrounding Soft Tissues by Incision and Separation. - IVhen the fissure is confined to the soft palate this may not be required, but if there is any tension in bringing the rawed edges together, an incision through the mucous membrane and submucous tissue made parallel to and about half or three-quarters of an inch external to the fissure upon each side will suffice to relieve it. If tension still exists after this procedure any tight muscular fibre may also be divided. When the hard palate is involved $I$ still advocate the procedure which I first practised in 1864, an account of which, with illustrated cases-the first cases successfully treated in Scotland-was published in the Edinburgh Medical Joumal for January, 1865. This procedure consists in first paring the edges of the fissure, making an incision on each side close to the gum, and extending from the canine tooth to the last molar and round it, if necessary, and then separating with a periosteal elevator all the soft textures, including the periosteum, from the bony palate, leaving them only attached in front and behind where the palatine vessels enter. In this way the pared soft textures forming the two edges of the fissure can be slid together without tension and sutured. In the same paper I advised that the entire fissure in both hard and soft palates should be united at one time, but cases are occasionally met with in which the soft palate is deficient, and if in such cases the hard palate is involved, it is better to close the fissure in the hard palate only, and supplement the doficient soft palate by a soft rubber artificial one.

c. Suture the Pared Edges in Position.-Horsehair or silkworm catgut sutures may be used, but when the fissure involves the whole of the soft palate or hard palate, I employ two or more silver wire sutures with intermediate sutures of horsehair. It is always well to insert a silver wire suture at the point where the hard and soft palates join, for the wound here not infrequently gives way a little unless its edges are properly rawed and kept firmly in position by a rigid suture.

Pusition, Ancesthesia, etc.-When operating upon cases of cleft palate, I always have the patient thoroughly under the influence of chloroform and resting upon his or her back, with the head lying over the edge of a table. This position does much to prevent the blood-which often at first flows frecly-passing down into the pharynx or air passages. A Smith's or other efficient mouth gag is a very essential aid in performing these operations, and should always be used. As some blood must pass down into the stonach, and may, afterwards, be either vomited up or passed by the bowel, it is well to warn the friends or attendants of the patient that this may occur.

\section{After-Treatment}

The principal points to be attended to are to feed the patient with fluid, and soft but nourishing food, such as milk, eggs beat up in milk, and soups, to wash or syringe out the cavity of the mouth several times daily with some mild antiseptic lotion, such as boracic acid solution, and to limit the amount of speaking as much as possible.

The stitches should not be removed for from two to three weeks after the operation according to the amount of healing of the wound. Some of them usually become loosened, and can then be removed, and it is quite common for one or more of them to give way, leaving a gap. If this gap is not extensive, it gradually contracts and heals, but if an opening becomes permanent it may be closed by the application of a hot wire, or if of some size, by a second operation.

After successful operation for cleft palate, the speech may, for a time, not be much improved, but it always is favourably altered, and the patients find that they can speak with more ease. Careful education in speaking and pronouncing words will much aid in improving articulation.

In conclusion, I may state that, having from time to time been consulted by adult patients suffering from congenital fissures of the hard palate, as to the possibility of improving their speech and making them more fit to take part in public positions, I have always advised a closure of the fissure by operation, and several of these patients have-as advisedbeen operated upon by me.

My experience of the result in connection with these cases encourages me to advise that, even in adults, the closure by operation of a congenital fissure in the palate enables the patient to speak with greater ease and with greater distinctness, both in private and public life.

[In connection with these remarks patients were brought before the class, the characteristic points of these deformities demonstrated, and the suitable operative treatment for their relief described.]

\section{THE TREXTMENT OF ANGULAR DEFORMITIES AT THE HIP-JOINT.}

Read before the New York State Medical Association, October 10th, 1893.

By REGINALD H. SAYRE, M.D., Orthopædic Surgeon, Bellevue Hospital, New York.

Lrke a very large proportion of the cases which come to the orthopædic surgeon for treatment, the best thing to do for angular deformities at the hip-joint is to prevent their occurrence by proper treatment in the first place, and I hold that any patient who has sufficient recuperative power to recover from an inflammation in the hip-joint should do so with the legs practically parallel, and in a straight line with the body. But it very frequently happens that cases are so treated that they do not recover in this favourable position ; but when the symptoms of active inflammation have all passed by, the limb is left in a practically useless condition from the amount of deformity present.

The treatment to be adopted in these cases differs with the nature of the disease which produced the deformity, and with the condition of the joint at the time the patient comes under observation, and these conditions vary so widely, that very different means must be adopted in different instances to 
secure a favourable result. Perhaps I can best make this clear by detailing the history of a few cases of different classes of injuries at the hip accompanied by subsequent distortion.

Case I.-D. D., Salt Lake City, Utah, a miner, aged about 45 years, stout, thick-set man, was seen in August, 1886. Nine months previously, while working in a coal mine, the ground gave way and fell upon him, burying him out of sight. It was estimated there wasabout five tons of earth in the mass which covered him. When dug out the left femur was found to be broken just above the knee, and the right foot injured. He was stooping when injured, and received the blow on the small of the back and buttocks. Was confined to bed for two months, and did not know whether his right

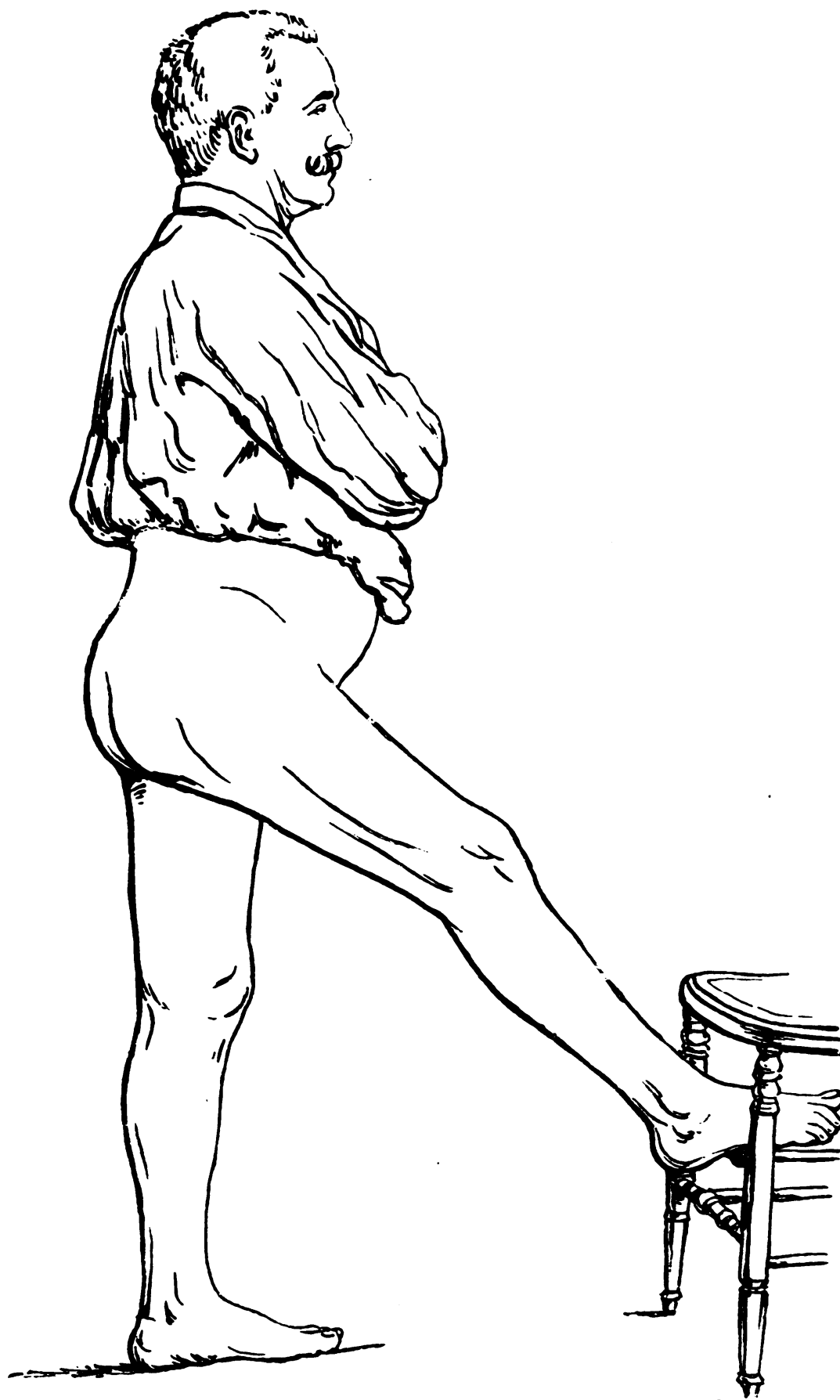

CASE 1.-(A) Fibrous ankylosis of the right hip, showing position of the limb before treatment, after nine months' ankylosis. This figure does not show position which this ankylosis caused when walking, which was much like figure $C$ of Case III.

hip was broken or not. Bedsores formed in less than two weeks, and the catheter was necessary part of the time, so that it is probable that his spinal cord was injured. When he finally got out of bed and moved about on crutches he could not move his right hip or knee, and his right leg seemed short to him. After consultation with various physicians, who decided that nothing had better be done, he was sent to New York.

He was a large, healthy-looking man, and, when first seen, walked with a very marked limp, using a cane to support himself, and stooping a great deal ; had very great difficulty in removing his clothes, as his right hip and knee were ankylosed, and the thigh flexed on the body at an angle of 30 degrees, and strongly adducted. Measurement of the limbs, as accurately as could be done in their distorted position, seemed to show that the shortening of the right leg was due simply to flexion and adduction. The left kuee could be flexed to a right angle and no more, on account of the callus formed by the old fracture just above the knee. The right hip and knee seemed to be firmly ankylosed, but on attempting to move the joints violently, while an assistant held the pelvis securely, more or less pain was caused, and I therefore concluded that the ankylosis was not bony. My experience in these cases is that if the ankylosis is bony,

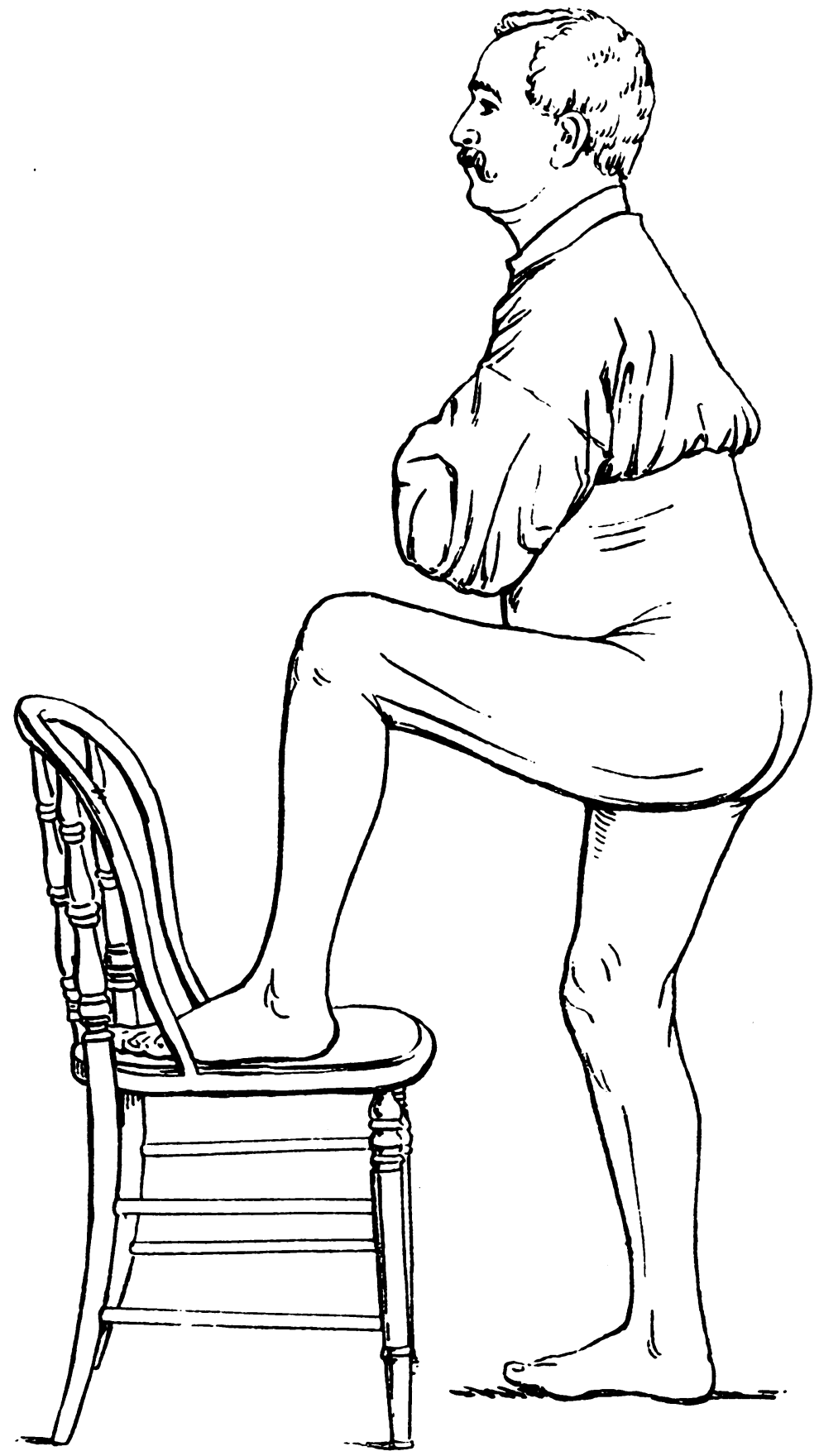

CASE 1.-(B) Result of massage in removing fibrous ankylosis o the right hip, which had been at an angle of 50 aegrees

efforts to move the joint are not attended with pain in the joint at the time or subsequently, and that if your efforts at movement are followed by pain, it is very certain proof that it, is simply strong fibrosis ankylosis, and that your efforts have caused more or less irritation.

Concluding in this case, therefore, that the ankylosis was only fibrous, I referred the patient to a friend for treatment, but he returned in a few days, saying that the doctor had advised him not to undergo operation, as the risk was more than the probable benetit. I decided in this case to use massage daily, and active and passive movements rather than to attempt to break up the joints by force. Slight movements 
were given to the knee and hip after the tissues in the neighbourhood of these joints had been thoroughly massaged every day; and in the course of a month I was able to bend the right knee to a right angle, and move the hip somewhat. The motions became freer and freer in these joints, until in two months from the time when the patient was put under treatment he could stand on either leg, and put the other foot on the seat of a chair in front of him, and could abduct his legs sufficiently wide to ride on horseback, and could cross one leg over the other, bringing the thighs close against the chest, and rise again without assistance.

From contraction of the psoas and iliacus muscles of the right side, which had not yet entirely relaxed, the right limb was a quarter of an inch shorter than the left, but with this amount of elevation on the sole and heel of his shoe he walked without hardly any limp, and returned to work. The accompanying photographs show the degree of movement.

Case II.-W. M., North Carolina, aged 23, had typhoid fever in the spring of 1893, and, after the fever had apparently passed by, was attacked with acute synovitis in the left hip, knee, and ankle. His family physician thought the joints would suppurate, but the inflammation eventually subsided without formation of any abscess. When seen by me in September, 1893, he was in a very emaciated condition, had marks of numerous old bedsores on his body, and walked with great difficulty by the aid of two crutches. His left thigh was rotated so far inward that the head of the femur could be distinctly felt posterior to the trochanter major. His excessive emaciation allowed the limb to be rotated inward almost as far as it is possible on a skeleton, bringing the left knee behind the right. The left foot, being turned at right angles to its normal position, has marked varus of the foot, very limited motion in the ankle-joint, and limited motion in the knee. The adductor tendons in this case were not tense, as in the preceding instance, the joint being held in its position apparently by thickening of the capsular ligament and adjacent structures. After handling and massaging the joint for a few days, having been able to satisfy myself that there was no bony ankylosis in the hip, I felt a slight movement and yielding of the bands that held the joint in its distorted position while I was manipulating the limb one day, and applied immediate force and brought the limb into a normal position, which was accompanied by a loud report, like a pistol shot, where some of the tight structures surrounding the capsule had given way.

I should have preferred to have used an anæsthetic on this patient, but, under the circumstances, when I felt part of the resistance yield, I preferred to break the joint completely, at once, and then immobilise it rather than to run the risk of setting up a fresh inflammation by irritating it slightly, and subsequently irritating it still further by divided attempts at reduction. As soon as I had brought the leg into a straight line with its fellow, and in a straight line with the body, I applied a hoop-iron splint, of the Thomas pattern, as well as an anterior wire splint to prevent, as far as possible, any movement in the joint. These cases of brisement forcé require absolute rest of the joint for ten days to a fortnight, and sometimes the addition of icebags to prevent subsequent inflammation, and movement should be deferred till pain and heat have ceased.

The joint was intensely painful for a couple of days following the operation, but inside of two weeks the pain had disappeared, and gradual motions were begun for the purpose of restoring the joint to its normal function, which are at the present time being continued.

CASE III.-W. H., North Carolina, aged 12, had hip disease between the ages of 3 and 4 ; was treated in a haphazard fashion with long traction splints improperly applied, and finally recovered in the position shown in photograph, the left thigh being flexed on the body at an angle of 50 degrees, adducted strongly as far as his flesh would permit, and apparently ankylosed. Examining the boy without an anæsthetic I thought I detected slight motion in the hip, and proceeded therefore to make a section of the ductor muscles and of the psoas and iliacus through an anterior incision, but found that I was unable (with any force which I felt justified in using) to break up the adhesions between the femur and acetabulum, I accordingly attempted to chisel the femur through just below the lesser trochanter, making use of the anterior incision which I had made for the purpose of cutting the psoas and iliacus muscles. When I had cut part way through the bone, very violent hæmorrhage commenced from a point a little below the smaller trochanter, and close to the under surface of the femur, which I was able to arrest only after tedious effort, the bleeding point having been caught by forceps being passed down very deep in the wound, and which I was obliged to leave fastened to this vessel, as I was unable to pass a ligature around their point. I presume that the edge of the chisel must have projected slightly

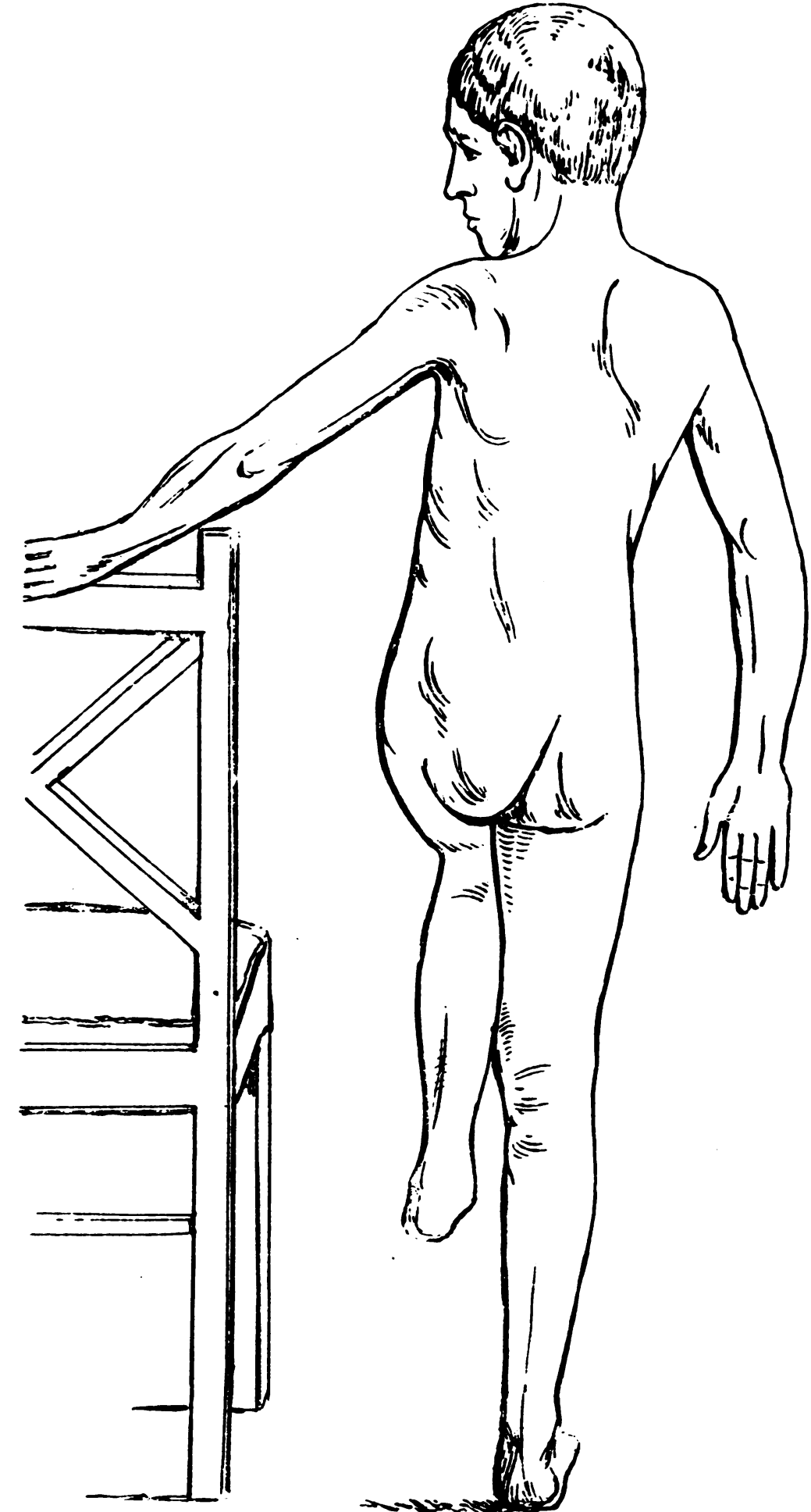

CASE III.-(B) Bony ankylosis of the left hip after hip-joint disease.

beyond the bone and cut the internal circumflex artery, or some branch of it. The wound was packed, leaving the forceps in position. The boy rallied well from the operation, and some weeks later, when the wound had healed, I did a subcutaneous osteotomy of the left femur, just below the trochanter minor, brought the leg into as nearly a normal position as possible, and applied a plaster-of-paris dressing from the toes to the arm-pits, strengthening it in front with a wire splint. By means of this plaster splint, the hip-joint was kept as nearly at rest as possible, while it was very easy to change the boy's position by means of a couple of swings passed around his body, and attached to a block and tackle 
which hung from a wooden frame over the bed. His recovery was uneventful, and in two months' time he was walking about on both legs, with a very trifling limp, in an erret position, as shown in photographs.

CAsE IV.-Miss Z., Wisconsin, aged 23, when about 12 years old had what was called an attack of rheumatism, which she attributed to getting wet by wading in a brook in the late Fall. Severe inflammat ion of both her hips, her right
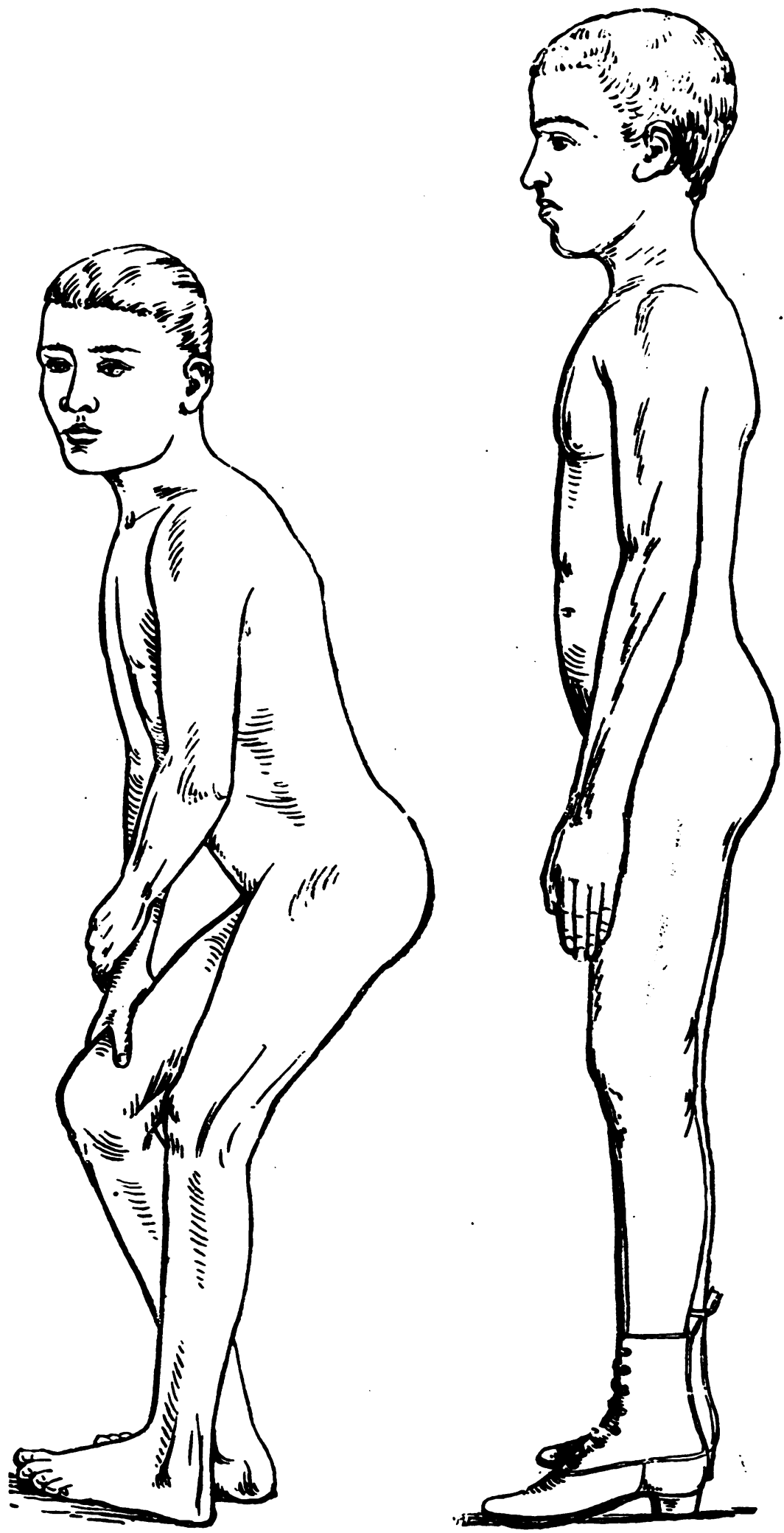

CASE III.-(C) Mode of walking with angular deformity of eft hip with bony ankylosis.

CASE III.-(D) Result of subtrochanteric ostcotomy for angular deformity with ankylosis of the left hip.

knee, and both ankles followed. The right ankle suppurated and bone was discharged from the sinuses. When seen by me, there were large scars on the sacrum and near the left Whether these were the result of old bedsores or an inflammation of the bone I was unable to determine from the history. She had bony ankylosis of both hip-joints, both thighs being flexed on the body at about 50 degrees, the right one abducted and the left strongly adducted. very much in the position she would assume if riding on a side saddle. The motion in the right ankle was quite limited, a large bony deposit in front of the astragalus preventing the foot from coming to a right angle with the leg. The motions in the right knee were also slightly limited; she walked with great difficulty by means of cane's, and presented a very distorted appearance.

After unsuccessfully attempting to break up the ankylosis
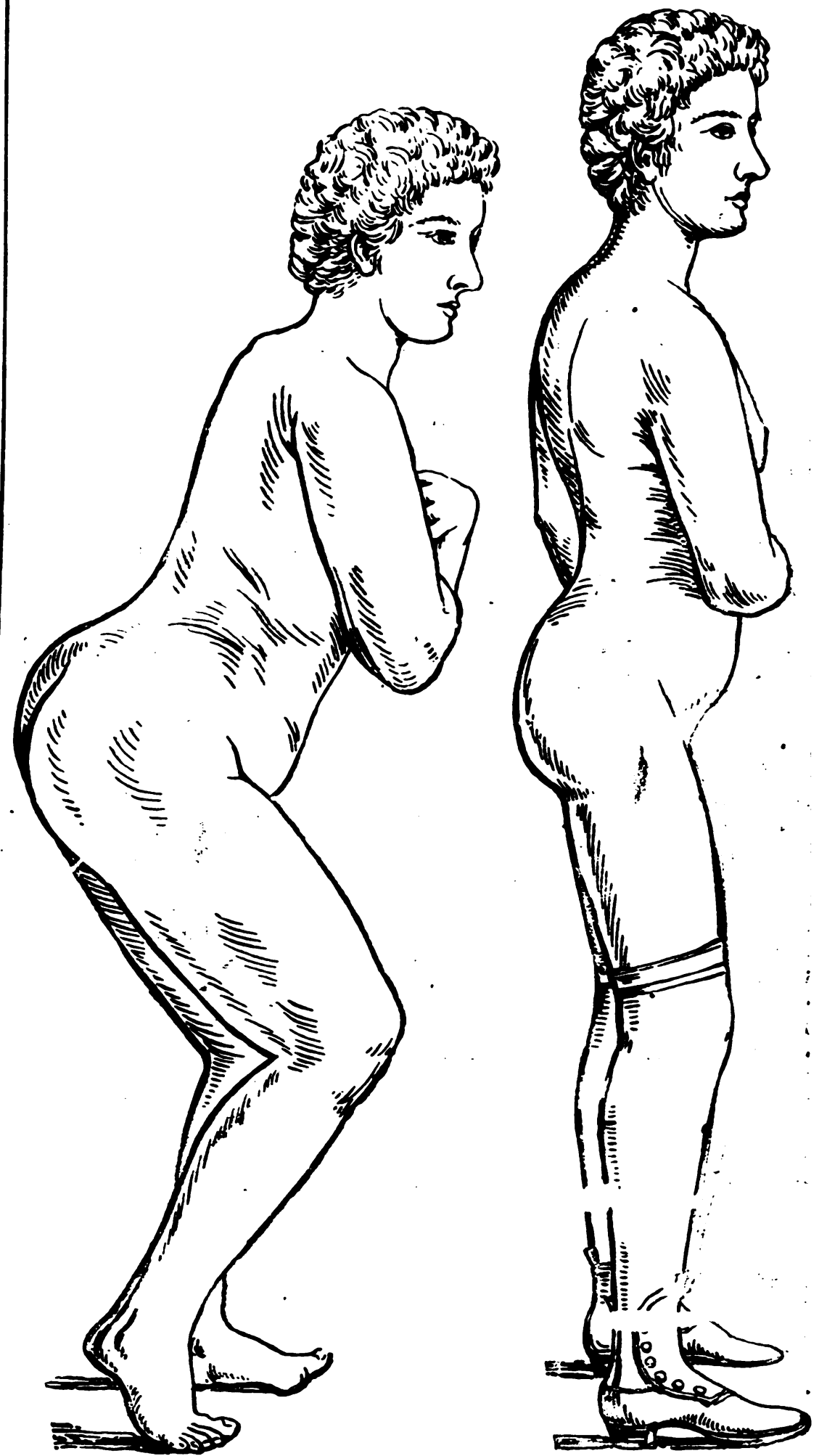

CaSe IV.-Bony ankylosis of both hips, with angular de for.. ity.

CASE IV.-Result of synchronous ostcotomy for bony anky:0 sis of both hips, with angular deformit $;$.

at the hips, the pelvis at this time being firmly secured to a table by large clamps, I made an incision over the left trochanter major as if to perform excision, thinking that it might be possible to chisel the head of the femur loose from its attachments and make a movable joint by digging out a. new acetabulum, but found the two bones uni:ed by so thick and extensive a deposit of new bone that this was impracticable. I therefore chiselled through the femur just below the smaller trochanter, brought the leg in straight line with 
the bcdy, and secured it temporarily with a wire splint ; having sewn up the incision-leaving one drainage tube in it, as there had been quite extensive laceration of the soft parts in exposing the joint-I then turned her on the other side and did a subcutaneous ostentomy, also below the smaller trochanter, without attempting to form a false joint, as I had proposed to do on the other side. This wound was closed and sealed with iodoform collodion. The patient was then encased in plaster-of-paris bandages from the armpits to the toes of both feet, the plaster being reinforced by iron wire splints laid on the front of each thigh and running up over the thorax, and secured by additional layers of plaster bandages.

I cannot too highly recommend this way of putting up osteotomies of the femur and also fractures of the femur high up, the ease with which patients can be shifted from one position to another and their necessary wants attended to being altogether greater than by means of any other dressings which 1 have tried. When the patient is an adult, weighing perhaps 180 pounds, it is very difficult for him to be moved except by means of a block and tackle attached to a stout beam over the bed, and unless a very rigid splint is applied the body is almost certain to bend at the hips when tie patient's weight liangs suspended by means of straps passing under the shoulders and lower extremities. I therefore reinforce the plaster with iron strips at the hips. It is of the utmost importance in these cases that the dressing should be sufficiently secure not to require readjustment until the fractured bone shall have had a chance to become consolidated.

The drainage tube was removed at the end of two days, the outer layer of gauze only being removed, as the end of the tube had purposely been left projecting through the inner layer of gauze. A fenestra was cut in the plaster to facilitate removal of the tube.

At the end of two weeks I cut the dressing in two on the right femur at the point where the hip and body join, and adjusted the position of the limb slightly, and rejoined the portions of this splint by new bandages and wire. The patient made an uneventful recovery, and her position before and after the operation is shown in the accompanying photographs.

From my experience in various cases of ankylosis about the hip, I have found that many of the distortions following hip disease, which are supposed to be due to contraction of the tendons around the joint, are in reality retained in place to a greater extent by the adhesions about the capsule and between the bones, and that in many cases the cutting of the tendons alone will be insufficient to allow reduction of the deformity. I believe it is a simpler and.safer operation in many cases to do a subcutaneous osteotomy below the trochanter than to endeavour to cut, either subcutaneously or through an open incision, the adhesions which bind the joint in its distorted position, and $I$ have learned that it is very easy to be mistaken in regard to the presence of movement in a joint, and we very frequently imagine that we feel a slight amount of motion in ankylosed hips, whereas the motion is really between the flesh and the bone or in the sacro-iliac synchondrosis, and even in joints which are more easily accessible (as the knee and elbow) I have seen men of large experience deceived in supposing that movement was present, when subsequent operation showed firm bony ankylosis.

In regard to the choice between osteotomy or brisement force, a good deal must be left to the judgment of the operator and the conditions of each individual case, and there are certain cases where I believe the dangers of re-exciting inflammation in the joint by brisement forcé are so great that I think it is safer to do an osteotomy, and if the joint is to be broken up, I believe in making section of all constricting bands which can be safely cut, breaking up the adhesions thoroughly under an anæsthetic, placing the limb at once in the required position, and then keeping the part absolutely at rest until all pain, swelling, and tenderness have subsided, and I find benefit in many instances from diminishing the blood supply to the joint by means of moderate compression over the artery supplying it with blood. After the joint is completely free from pain slight motions should be given every day to restore to function, but never carried to the point of producing pain or tenderness which will last as long as twenty-four liours. If your efforts to restore func$t$ ins are followed by increased heat or tendermess, cease your manipulations and he content with the improved position and a stiff joint. If, however, as in Case 1, there is slight motion in the joint and the employment of gradual manipulation and massage is not followed by inflammatory reaction, continue the procedures daily, increasing in force and frequency as experience warrants, and in many instances you will be able to cause absorption of inflammatory deposits, break down old adhesions, and restore excellent motion to joints which have been considered useless for montlis and sometimes for years.

\section{REMARKS MADE AT THE BEDSIDE OF A PATIENT SUFFERING FROM LEAD ENCEPHALOPATHY.}

\author{
BY STEPHEN MACKENZIF, M.D., F.R.C.P., \\ Physician to and Lecturer on Medicine at the London Hospital ; \\ Physician to the Royal London Ophtha:mic Hospital.
}

E. C., aged 26, was admitted into the London Hospital under my care on October $27 \mathrm{th}, 1893$, and the following history and notice of the case were taken by Messrs. Palmer and A. L. Smith.

The family history has no bearing on the case. The patient was born at Poplar, and lived there until 14 years of age, when she went into service as a helper at a cofiee shop. She married at 17, and has had seven children and several miscarriages. Only one of the children is living now, aged 9 years; the remainder only lived a few days. She has been of temperate habits. She has lived badly, having meat only once a week as a rule. She has lately been employed in lead works, but has only followed this avocation for three weeks. She was engaged in the manufacture of white lead. Two months before her illness she had an attack of pain in the chest, and vomited about a tablespoonful of thick dark blood. This happened only once, and she has never been laid up, except with her confinements and miscarriages.

She states that she was quite well on Sunday, October 16th. The next day she went to work, but, to use her own words, "did not feel very grand." On the Tuesday and Wednesday she had the same feeling of weakness and pains in her limbs; she felt it was too much trouble even to comb her hair. On the Thursday, October 20 th, more urgent symptoms arose. At 8 in the morning some breakfast was got ready for her, but she felt so sick she was quite unable to eat it. What she vomited was white froth-no blood. She took no solid food, and any liquid she took was immediately vomited. On the Friday she brought up some blood, about a tablespoonful ; it was pale and tasted sweet. This was the only occasion on which she vomited blood, but the vomit consisted of froth, and was incessant, at least fifty times a day. The day before admission it became greenish.

She lies in bed on one side, markedly anæmic but not cachectic. She complains of constant and severe headache, which she localises chiefly in the occipital region. It is evi. dently, from her appearance of suffering, very severe. She vomits every few minutes, the vomited matter consisting chiefly of yellowish-green froth and fluid. The bowels are confined, the tongue is furred, and along the edge of the gums of some of the teeth only there is a faint but distinct blue-black line. The abdomen is not distended but is slightly tender, as is the liver, which is of normal size. The heart's position and dulness are normal ; the first sound at the apex is murmurish; the precordial region is tender, the pulse is 75 , the tension rather below the normal. She is intelligent but very much oppressed with the headache, which has never left her since it commenced. It is chiefly occipital, but extends from thence over the vertex to the frontal region. She no sooner takes anything into the stomach than it returns, and is frequently sick without taking anything. The vomit amounts to 3 or 4 pints per diem; it is acid, bile-stained, and frothy. The pupils are large, ind react to light and accommodation. There is internal strabis nus of the right eye, the result of an accident when 15 years old. Onhthalmoscopical examination showed srelling of each optic papilla, indis- 